\title{
Learning style preferences among second year medical students in Rajarata University of Sri Lanka
}

\author{
Vijithananda HHTSM ${ }^{1}$, Senarath DMKN ${ }^{1}$, Perera HTC ${ }^{1}$, Dharmarathne KND ${ }^{1}$, \\ Abeyrathne IANP ${ }^{1}$, Adikari SB ${ }^{1}$, Paththinige $\mathrm{CS}^{1}$, Jayawardana SMA ${ }^{1}$ \\ ${ }^{I}$ Department of Anatomy, Faculty Medicine and Allied Sciences, Rajarata University of \\ Sri Lanka \\ *sahan.vijithananda@gmail.com
}

Current medical students are a diverse group in terms of level of preparedness for learning and the learning preferences. It is the responsibility of teachers to address the diversity of learning needs and preferences among students and to take appropriate teaching approaches to improve their education. This study aimed to assess the learning styles of 2 nd year medical students of the Faculty of Medicine and Allied Sciences, Rajarata University of Sri Lanka (FMAS, RUSL). A descriptive cross-sectional study was conducted among two batches of students in FMAS, RUSL after completion of the pre-clinical course. The Visual, Auditory, Read/Write, Kinesthetic (VARK) questionnaire, which is a validated tool for the assessment of learning preferences was administered to all the students in 2 batches, after obtaining informed written consent. The data were analyzed and presented using descriptive statistics, according to the guidelines in VARK website. The questionnaire was distributed to 347 students, and response rate was $88.2 \%$ $(\mathrm{n}=306)$. Among the respondents, $57.3 \%$ preferred a single mode of information presentation (V, A, R or $\mathrm{K})$; $9.3 \%$ preferred visual (learning from graphs, charts, and flow diagrams), $21.7 \%$ preferred auditory (learning from speech), 12.1\% preferred printed words (learning from reading and writing), and $14.2 \%$ preferred using all their senses (kinesthetic: learning from physical involvement- touching, doings, and manipulation). Of the respondents, $42.7 \%$ preferred the multiple modes of information presentation. This included $34.7 \%$ of bi-modal learners, $7.0 \%$ of tri-modal learners and $1.0 \%$ of quadmodal learners.

Second year medical students in FMAS, RUSL have a variety of learning styles indicating the preference to different modes of information presentation in their learning. To meet these needs, teaching should be multisensory and should include a variety of teaching learning modalities to enrich the students' learning experience. 